
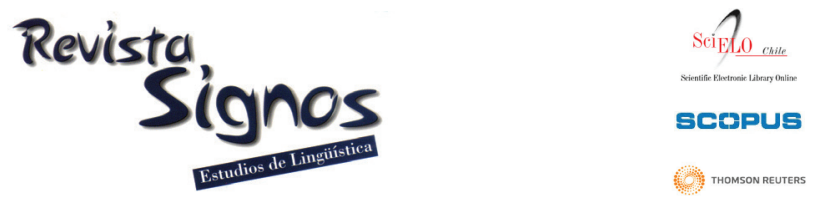

Meyer, M. (2013)

\title{
Principia Rhetorica. Una teoría general de la argumentación
}

\author{
352 pp. Buenos Aires: Amorrortu \\ ISBN: 978-950-518-353-1 \\ Giohanny Olave \\ Universidad de Buenos Aires/conicet \\ Argentina \\ olavearias@gmail.com
}

Recibido: 08-IV-2013 / Aceptado: 16-XII-2013

La aparición en español de esta obra de Michel Meyer (2013) es recibida con mucho interés por parte de los analistas del discurso en Latinoamérica, especialmente en el campo de la argumentación y la retórica. Es la traducción de la obra original en francés, publicada en 2008 por la editorial Fayard, en París, y traducida con el apoyo del Programa de Ayuda a la Publicación Victoria Ocampo, de la Embajada de Francia y el Instituto Francés, en Argentina. En efecto, el interés en este libro de Meyer (2013) responde a la limitada disponibilidad de sus obras en la región ${ }^{1}$, aun en lengua francesa, pese a ser una de las figuras intelectuales más activas actualmente en la filosofía y las ciencias del lenguaje en el ámbito francófono, particularmente por la creación y desarrollo a lo largo de más de quince años de la perspectiva 'problematológica' del discurso.

Se trata de un enfoque que ubica al cuestionamiento en el centro de la reflexión. Meyer (2013) propone volver a pensar la racionalidad dominante heredada de Platón y Aristóteles, advirtiendo que tal modelo persigue la eliminación de la interrogatividad e instaura lo resolutorio como norma del pensamiento. La problematicidad del mundo, de los otros y de uno mismo -señala el autor- se sitúan en la base de una epistemología, una estética y una retórica originales; de allí que Principia Rhetorica haga parte de un proyecto filosófico de largo alcance. 
Vista desde la problematología, la retórica será una disciplina que incluye a la argumentación y que se interesa por las cuestiones (problemas) que unen o separan a los individuos. La retórica permitiría poner en evidencia las preguntas subyacentes que han sido desplazadas por la primacía de sus respuestas. Cuando las relaciones entre ethos, pathos y logos se manifiestan como procedimientos que pretenden desviar o negar la existencia de esas preguntas y problemas, presentándolos como si ya estuviesen resueltos, se está en el terreno de la retórica. Cuando, por el contrario, se 'ponen las cuestiones sobre la mesa' para resolver la diferencia entre individuos, se habla de argumentación. Con esta diferenciación básica, el autor toma distancia del trabajo de Perelman (Perelman \& Olbrechts-Tyteca, 1989[1958]), su maestro y predecesor en la Universidad Libre de Bruselas.

Meyer (2013) entiende la diferencia entre visiones de mundo en términos de distancia intersubjetiva (psicológica y social), y la presenta como clave para entender los elementos del triángulo retórico. Así, el énfasis ya no recae sobre alguno de los elementos aislados, sino en las variaciones entre los vínculos o relaciones entre ellos. El libro está dedicado a explicar esas variaciones al proponer una visión integral de la retórica como gestión simultánea del ethos, el pathos y el logos; el siguiente concepto pretende condensar esa gestión y la obra se dedica a desplegarlo en profundidad: "La retórica es la negociación de la distancia entre individuos acerca de una cuestión dada, más o menos problemática" (Meyer, 2013: 347).

El primer capítulo revisa sintéticamente las definiciones precedentes sobre retórica, desde el mundo antiguo hasta el siglo XX. En esta revisión se demuestra el mayor énfasis puesto en el orador, el auditorio o el lenguaje/estilo en las diferentes visiones teóricas, lo cual hace que no den cuenta de la retórica como unidad. El recuento desemboca y respalda la definición integral que propone Meyer (2013). La hipótesis, que queda pendiente por probar en análisis empíricos extendidos y con corpora auténticos, es que si el objeto de estudio es la distancia, los componentes del triángulo retórico pueden analizarse en pie de igualdad.

En el segundo capítulo se despliega históricamente la visión problematológica. Para hacerlo, aparecen aquí las lecturas de Meyer (2013) sobre las obras de mayor peso en la tradición argumentativa y retórica, desde Platón hasta Van Eemeren y Grootendorst. En ocasiones, puede parecer que el afán es más clasificatorio que analítico; por ejemplo, al arriesgar una rejilla que separa a los autores en retóricos y argumentativos, por un lado, y en énfasis teóricos en el ethos, el pathos o el logos, por el otro. No obstante, Meyer (2013) logra situar esos resurgimientos históricos de la retórica en relación con las crisis de paradigmas y la relativización de certezas, cuando las respuestas van dejando de serlo y devienen en cuestiones nuevas. Tales momentos críticos establecen 'diferencias problematológicas' (différences problématologiques) al desanudar el par cuestión/respuesta en las proposiciones. El autor denomina 'represión problematológica' (refoulement problématologique) a esa fuerza diferenciadora, ejercida por las crisis paradigmáticas en 
la historia y en tensión constante con la fuerza de indiferenciación que se le opone, o 'represión apocrítica' (refoulement apocritique). Hay que señalar una dificultad en este capítulo, que puede crear confusiones para la comprensión del resto de la obra: el sentido con que el autor utiliza el sustantivo refoulement, que no da cuenta de una 'represión' (como fue traducido desafortunadamente), sino más bien de una fuerza divisoria para la amalgama cuestión $/$ respuesta $^{2}$, como se infiere a partir de la obra completa.

El siguiente par de capítulos caracteriza el razonamiento argumentativo y retórico, su estructura formal y el funcionamiento de sus componentes. Estas formas y procesos se sostienen sobre dos leyes: la de 'unidad del campo', que plantea un continum entre retórica y argumentación, graduado por el contexto como saber compartido acerca de la cuestión en juego; y la ley de 'distancia entre individuos', que explica el pasaje del énfasis en la cuestión al énfasis en los sujetos, cuando la primera no puede resolverse apelando al logos. Ese deslizamiento es el que pretende volver no problemático lo problemático, a través de la modulación de la identidad y la diferencia operada por los lugares comunes (topoï) y la racionalidad 'desproblematizante' de las figuras retóricas. El tratamiento de esas figuras y lugares es lo más interesante de esta sección, porque no se detiene en una taxonomía que diría muy poco a la hora de analizar discursos, sino que Meyer (2013) reconstruye las lógicas de la figuratividad y de la tópica al servicio de la proximidad o la distancia con el auditorio.

El quinto capítulo constituye una relectura del ethos, el logos y el pathos, en clave problematológica. Desde esta perspectiva, el primero refiere el mayor o menor acercamiento al auditorio con base en la autoridad, humanidad y sentimiento de comunión que muestre el orador. El rol de los valores es fundamental, entonces, para entender ese doble sentido ético y estratégico del ethos en la interacción retórica. El segundo, es el lugar donde se negocia la diferencia cuestión/respuesta; Meyer (2013) observa que en los estudios precedentes, la dualidad problematológica y apocrítica de las respuestas ha reenviado más a lo resolutorio que a la interrogatividad implícita que ellas contienen. Cuanto más universalista resulte el logos -concluye el autor- más distancia intersubjetiva establece, y por tanto, menos posibilidad existe de negociar la diferencia.

El pathos, finalmente, es la manera como el auditorio 'padece' una cuestión y ve afectado su juicio vía la emoción; las pasiones son determinantes para la acercamiento del orador al auditorio, de modo que cuanto más fuerte es la pasión, más débil es la distancia. El problema estriba en que las pasiones intensas, al proceder lo mismo que las figuras retóricas, transforman en respuesta el orden de la interrogación, y por tanto, inmovilizan las posiciones en el debate y bloquean la capacidad de captar la lógica del otro. Aquí el autor utiliza la expresión 'diálogo de sordos' (Meyer, 2013), que el tratado de retórica de Angenot (2008) - contemporáneo a este tratado de Meyer (2013) pero no citado-, utiliza como prueba empírica de la imposibilidad de un 
logos resolutorio. Es interesante que Meyer (2013) aborde esta cuestión centrándose en el tercero: su función, -propone- es la de encarnar valores que des-subjetiven la oposición y permita a los interlocutores volver a escucharse. Lamentablemente, este apunte más dialéctico de la dinámica retórica, queda sin desarrollar.

El sexto capítulo está dedicado al examen de la relación entre valores y pasiones en las esferas del sistema social. Dado que su diferencia esencial radica en la negociabilidad de las segundas, frente a la pretensión de universalidad de los primeros, Meyer (2013) presenta la pasión como un valor reducido a la reacción subjetiva, y viceversa, el valor como la pasión vaciada de subjetividad y emocionalidad. El orador, entonces, utiliza ese juego entre valores y emociones para anular el efecto de distanciamiento entre él y su auditorio. La conflictividad, inscrita en los desacuerdos en materia de valores, radica pues en las contradicciones entre ethos y pathos frente a cuestiones dadas, una variación que va de la identidad a la diferencia y de lo individual a lo colectivo. La vida en sociedad está fundada sobre esas tensiones que la retórica, como procedimiento, se encarga de negociar alejando, aproximando o anclando las posiciones de los sujetos en divergencia.

El siguiente capítulo explica ese proceso de negociación. Meyer (2013) retoma el modelo del 'circuito retórico', ya expuesto en La rhétorique (2004), como un ciclo de desajustes y ajustes entre orador y auditorio. Las situaciones de desacuerdo manifiestan las diferencias entre ethé y pathé proyectivos y efectivos, es decir, la disimilitud entre lo mostrado y lo esperado, tanto por el orador como por el auditorio. Ni el auditorio imaginado por el orador (pathos proyectivo) ni el orador imaginado por el auditorio (ethos proyectivo), coincidirán exactamente con los sujetos 'reales' que hablan y escuchan (ethos y pathos efectivos), pero es la conciencia de esa distancia la que dinamiza el proceso de negociación y renegociación de imágenes. La manipulación, el malentendido y los prejuicios, entre otros, son fenómenos explicables a partir de los diferentes desajustes en el circuito, así como los géneros retóricos, que ya no se definirían en relación con el tipo de conflictividad (anulada o resuelta), sino en función de las estrategias del orador para gestionar la distancia respecto de sí mismo y del otro. Pese al importante desarrollo de las nociones de ethos y pathos en el ámbito francés contemporáneo de la argumentación y la retórica (Amossy, 1999, 2000, 2010; Angenot, 2008; Danblon, 2005; Maingueneau, 2002; Plantin, 2005), sorprende un poco la falta de diálogo del autor con estos avances, sobre todo para complejizar la relación entre sujeto discursivo (inscrito en el enunciado) y sujeto empírico (exterior al enunciado), y entre ellos con el logos, que en la negociación de la distancia intersubjetiva parece quedar simplificado en una función representacional.

El octavo capítulo plantea dos variaciones problemáticas centradas en el logos y enunciadas en forma de leyes. La primera, o 'Ley de contextualidad' (Loi de contextualitê), explica cómo la razón y el discurso han sido considerados en un orden proposicional que borra las preguntas originarias (aquello a lo que responde implícitamente una 
proposición), en función de lo que el contexto hace dar por sentado. La segunda, o 'Ley de problematicidad invertida' (Loi de problématicité inversée), expresa una relación inversamente proporcional entre literalidad del problema e incremento figurativo del logos. La figuratividad acentuada, como en el caso de la literatura, conlleva la búsqueda de las cuestiones que originan el texto, a partir de lo que él presenta como respuestas; de ahí que la hermenéutica -indica el autor- sea una disciplina esencialmente interrogativa y sus operaciones (comprensión, interpretación y aplicación) guarden correspondencia con el logos, el ethos y el pathos, respectivamente.

En lo que sigue, el autor va a explorar el funcionamiento de las leyes, enunciadas antes, en el derecho, la política, la publicidad y la economía, como instituciones oratorias'. Aquí sigue a Quintiliano para entender tales instituciones como "lugares privilegiados de la palabra social o individualizada" (Meyer, 2013: 292). Evidentemente, las distancias se juegan de modos distintos en esos lugares, pero el aporte más potente consiste en mostrar las proyecciones y deslizamientos entre unos y otros, en términos de ethos y pathos efectivos y proyectivos. La 'retorización' de las cuestiones consiste, pues, en una des-problematización de la conflictividad (hiatos entre lo efectivo y lo proyectivo) mediada por esos 'lugares de habla', o instituciones oratorias, en constante imbricación.

El capítulo nueve intenta conjugar las instancias y las instituciones oratorias en gráficos de doble eje, con dos vectores cruzados, donde se visualizan las variaciones de los dos tipos de distancias que propone Meyer (2013): social (que señala las diferencias socio-históricas de estatus y es diacrónica) y psicológica (que señala las diferencias afectivas entre los sujetos y es sincrónica). En el sistema propuesto, el logos es el centro o intersección entre los vectores, y se plantean situaciones de interacción variadas para ilustrar los cambios en la proximidad entre ethos y pathos. Los cuadrantes que resultan del sistema representarían los espacios discursivos en donde median las instituciones oratorias, como la política o el derecho, para recrear la autoridad y resolver las cuestiones. Es interesante el intento de graficar a través de vectores y planos las relaciones entre distanciamientos, instancias e instituciones retóricas, para esclarecer las complejas correlaciones inferidas por el autor. No obstante, es ambiguo el tratamiento gráfico de los vectores que indican distancias: ¿cómo representarlas sin indicar posicionamientos concretos de los sujetos? ¿Por qué los vectores solo indican aumentos del pathos? ¿Es el logos solo un punto por donde 'cruzan' el ethos psicológico y el social? ¿Por qué en uno de los esquemas (Meyer, 2013: 319 (cuadro 36); Meyer, 2008: 290) el logos ocupa el lugar del pathos? Entre otros interrogantes que requerirían abordajes más detenidos.

El último capítulo cierra la obra con una reflexión meta-disciplinar que retoma la dinámica histórica de la represión problematológica (fuerza diferenciadora) frente a la represión apocrítica (fuerza indiferenciadora). La capacidad de diferenciar y de amalgamar cuestiones y respuestas, de problematizar y des-problematizar, está en el 
centro de la retórica, y por tanto, constituye su doble filo. Enseguida, el autor demarca tres estadios que se nutren de retóricas y valores específicos en la contemporaneidad: la religión, la política y la individualidad, que corresponderían a los dominios de lo sagrado, lo deóntico y lo psicológico, influyentes en la negociación de las distancias intersubjetivas. El capítulo finaliza con un interrogante fundamental: “Para qué sirve la retórica en nuestra sociedad posmoderna?” (Meyer, 2013: 341); la respuesta planteada tiene que ver con ese doble filo mencionado más arriba. Ella puede entronizar nuevos discursos unificadores y únicos, que reemplacen los viejos relatos menoscabados de la modernidad, o bien, desenmascarar esas pretensiones homogeneizadoras, problematizando los discursos que las sostienen. Ambas posibilidades meta-retóricas tensionan la comunicación y el encuentro de una ética de la discusión, más allá de la perspectiva consensualista habermasiana. De ambas posibilidades, además, emerge el tenue juego de la distancia intersubjetiva, y en sus dinámicas, las posiciones encontradas acerca de su legitimidad, la oposición y la disputa. En el resurgimiento constante de estas diferencias, los estudios retóricos tienen bastante por decir, más allá de la manipulación, la persuasión o la toma de partido.

Finalmente, Meyer (2013) incluye un breve glosario de conceptos básicos utilizados a lo largo de la obra. Dada la complejidad del tratado, se extraña la inclusión de una cantidad más generosa de términos y la falta de complementariedad de algunas duplas, como las nociones de represión problematológica y apocrítica, de las cuales solo se incluyó la primera. En el mismo orden paratextual, la edición en español omitió el índice analítico de la versión original (Meyer, 2008a, 2008b), supremamente útil para el manejo del contenido.

Con todo, Principia Rhetorica cumple con la tarea de abandonar el reduccionismo de una retórica centrada en la persuasividad o anclada en la visión esteticista de las figuras. La aspiración de Meyer (2013), de hecho, es bastante amplia, pues el enfoque problematológico le sirve para integrar dimensiones más allá de los límites disciplinares de la política, el derecho y la literatura; integralidad que se posibilita por la reflexión centrada en la negociación de la distancia entre ethos, pathos y logos, en las instituciones oratorias contemporáneas. Si bien su especificidad y densidad teórica no permiten verlo como un libro de fácil lectura, este Tratado constituye la puerta de entrada más clara, aplicada e integral al enfoque problematológico de Meyer (2013), una alternativa interesante para pensar la realidad social a través de preguntas que la problematizan, en vez de analizarla por medio de respuestas acabadas que la presentan como si ya estuviera resuelta. 


\section{REFERENCIAS BIBLIOGRÁFICAS}

Angenot, M. (2008). Dialogues de sourds. Traité de Rhétorique Antilogique. Paris: Mille et Une Nuites.

Amossy, R. (Ed.) (1999). Images de soi dans le discours. La construction de l'ethos. Laussane: Delachaux y Niestlé.

Amossy, R. (2000). L'argumentation dans le discours. París: Nathan.

Amossy, R. (2010). La présentation de soi. Ethos et identité verbale. París: PUF.

Danblon, E. (2005). La fonction persuasive. Anthropologie du discours rhétorique: Origines et actualité. París: Armand Colin.

CNRTL (Centre National de Ressources Textuelles et Lexicales) (2012). Refoulement [en línea]. Disponible en: http://www.cnrtl.fr/definition/refoulement

Jeuge-Maynart,I. (2008). Refoulement. Larousse, Dictionnairefrançais [enlínea]. Disponible en: http://www.larousse.fr/dictionnaires/francais/refoulement/67523

Maingueneau, D. (2002). Problèmes d'ethos. Pratiques, 113/114, 55-67.

Meyer, M. (1987 [1982]). Lógica, lenguaje y argumentación. Buenos Aires: Hachette.

Meyer, M. (1996 [1995]). De la insolencia: Ensayo sobre la moral y la política. Barcelona: Ariel.

Meyer, M. (2001 [1991]). Por una bistoria de la ontología. Barcelona: Idea Books.

Meyer, M. (2004). La Rhétorique. París: P.U.F.

Meyer, M. (2008a). Principia Rhetorica. Une théorie générale de l’argumentation. París: Fayard.

Meyer, M. (2008b [1986]). De la problématologie: Langage, science et philosophie. París: P.U.F.

Meyer, M. (2010a). La problématologie. Paris: P.U.F.

Meyer, M. (Dir.) (2010b [1994]). La filosofía anglosajona. Buenos Aires: Prometeo.

Meyer, M. (2013). Principia Rhetorica. Una teoría general de la argumentación. Buenos Aires: Amorrortu.

Perelman, Ch. \& Olbrechts-Tyteca, L. (1989 [1958]). Tratado de la argumentación. La nueva retórica. Madrid: Gredos.

Plantin, C. (2005). L'argumentation. Histoire, théories, perspectives. París: P.U.F. 


\section{NOTAS}

1 En el mercado hispanohablante se cuenta con tres traducciones de sus obras, de difícil consecución: 'Lógica, lenguaje y argumentación', original de 1982 (Buenos Aires: Hachette, 1987); 'De la insolencia: ensayo sobre la moral y la política', de 1995 (Barcelona: Ariel, 1996) y 'Por una historia de la ontología', de 1991 (Barcelona: Idea Books, 2001). Existe también traducida una compilación de trabajos dirigida por Meyer (2010b) bajo el título 'La filosofía anglosajona', original de 1994 (Buenos Aires: Prometeo, 2010b). Las principales obras sobre la teoría problematológica no tienen traducción al español: De la problématologie: langage, science et philosophie (Mardaga, Bruxelles, 1986; reimpresión: París: P.U.F., 2008b) y La problématologie (París: P.U.F., 2010a).

2 Las demás acepciones disponibles, como 'inhibición', 'rechazo', 'expulsión', ‘compresión' y 'retroceso' (cnrtl, 2012; Jeuge-Maynart, 2008); tampoco ayudan a comprender los sentidos de le refoulement problématologique et apocritique; por el contrario, los subvierten. 